\title{
EDITORIAL
}

\section{La crisis de la confianza}

Durante estos años y especialmente en los últimos meses hemos sido testigos de cómo son cuestionadas, con menor o mayor fundamento, numerosas de nuestras instituciones. Desde empresas de particulares hasta los partidos políticos, desde las oficinas de gobierno hasta la Iglesia Católica, desde los aeropuertos hasta el Registro Civil, el convencimiento de que nuestras instituciones funcionan se ha ido perdiendo entre frases que incluyen palabras claves como malversación, colusión o cohecho para describir las acciones que afectan a toda nuestra sociedad.

En medio de este escenario y, probablemente bastante ajenos al devenir de los cuestionados, nos enfrentamos a diario con el desafío de entregar información sobre los pacientes que nos son confiados. Precisamente es la dependencia de los enfermos y de sus médicos tratantes respecto de nuestras acciones y decisiones lo que abre un frente más para la confianza. ¿Cuánto vale entonces, cada uno de nuestros informes, en el entendido de que nuestras afirmaciones serán certezas sobre las que se decidirán tratamientos y se planificarán las acciones médicas?

Debemos tener en cuenta que el decaimiento moral de las organizaciones socava también las creencias interpersonales. Luhmann, sociólogo alemán, deja de lado al individuo como unidad básica de la construcción social y establece a las comunicaciones como las unidades constituyentes y reproductoras de los sistemas sociales. Debemos entonces mantener un flujo creíble de información para insertarnos y mantenernos como constituyentes confiables.

¿Qué sabemos del sistema en el que nos movemos como especialistas? Sabemos que nuestra tecnología disponible crece en forma exponencial, que la información médica se duplica cada cinco años, que una de cada cinco decisiones médicas está rigurosamente basada en la evidencia y que se estima que especialistas entrenados enfrentan una duda cada dos pacientes. El valor de nuestros informes, analizado dentro de un sistema de confianzas, va obviamente más allá del papel que lo contiene, porque implica la comunicación honesta de nuestros conocimientos, actualizados e integrados, para colaborar en la recuperación de la salud de aquellos que nos importan.

Dr. Marcelo Gálvez M.

Editor Científico 